\title{
Políticas públicas para a Educação Profissional no Brasil (1988- 1998)
}

\author{
Public policies for Professional Education in Brazil (1988-1998)
}

Recebido: 10/06/2020 | Revisado: 29/07/2020 | Aceito: 26/10/2020 | Publicado: $01 / 03 / 2021$

\author{
Vanessa Cauê Krugel \\ ORCID: https://orcid.org/0000-0003-0447- \\ 402X \\ Instituto Federal de Educação, Ciência e \\ Tecnologia do Paraná \\ E-mail:vanessacaue@msn.com \\ Wilson Lemos Junior \\ ORCID: https://orcid.org/0000-0000-0000- \\ 0000 \\ Instituto Federal de Educação, Ciência e \\ Tecnologia do Paraná \\ E-mail: wilson.lemos@ifpr.edu.br \\ Como citar: \\ KRUGEL, C. V.; JUNIOR LEMOS, W.; \\ Políticas públicas para a Educação \\ Profissional no Brasil (1988-1998). Revista \\ Brasileira da Educação Profissional e \\ Tecnológica, [S.I.], v. 1, n. 20, p. 1-13, \\ e10527, mar. 2021. ISSN 2447-1801.
}

This work is licensed under a Creative Commons Attribution 4.0 Unported License.

\section{Resumo}

Esse artigo trata das políticas públicas para a educação profissional entre 1988, data em que se deu a redemocratização do Brasil até a desarticulação entre o Ensino Médio e a Educação Profissional, ocorrida no ano de 1998. Por meio de análise bibliográfica e documental, objetiva-se contextualizar 0 cenário da educação profissional de nível técnico no Brasil, evidenciando a relação entre a Constituição Federal, a Lei de Diretrizes e Bases da Educação Nacional (LDBEN) de 1996 e do Decreto no 2.208, de 17 de abril de 1997, que desautorizou o ensino de $2^{2}$ Grau ao profissionalizante nas escolas de todo o país. De acordo com a Portaria do MEC no 646 de 14 de maio de 1997, o ingresso dos estudantes deveria ocorrer ou de forma concomitante ao ensino médio ou pósmédio, dando materialidade legal à enraizada dualidade estrutural na educação brasileira. O ensino médio integrado sofreu grandes ataques nesse período, mas também fortaleceu sua luta que veio a ser uma ferramenta importante para conquistas futuras.

Palavras-Chave: Ensino Médio; História da educação; Ensino Profissionalizante.

This article deals with public policies for professional education between 1988, the date when the redemocratization of Brazil took place, until the disarticulation between High School and Professional Education, which occurred in 1998. In order to contextualize the education scenario professional of Brazilian technical level, through bibliographic and documentary analysis, it is sought to evidence the relationship between the Federal Constitution, the Law of Directives and Bases of National Education (LDBEN) of 1996 and the decree 2.208 of April 17, 1997, decree the one that disallowed high school teaching to the professional level in schools across the country. According to MEC Ordinance no. 646 of May 14, 1997, student enrollment should occur either concurrently with secondary or post-secondary education, giving legal materiality to the rooted structural duality in Brazilian education. Integrated high school underwent major attacks in this period, but it also strengthened its struggle, which became an important tool for future conquests.

Keywords: High School; History of education; Vocational Education. 


\section{INTRODUÇÃO}

Esse artigo expõe aspectos das políticas públicas para a educação profissional entre 1988, data em que se deu a redemocratização do Brasil, até desvinculação entre o Ensino Médio e a Educação Profissional, ocorrida no ano de 1998. Inicialmente, trata-se da relação entre a Constituição de 1988 e a educação profissional. Esse período é marcado por muita luta no campo progressista, apesar disso, as discussões sobre a nova LDB começaram a ser traçadas nesse período sob fortes interferências de organismos internacionais.

No ano de 1995, houve uma tentativa de desvincular a educação profissional do Ministério da Educação e transferi-la para o Ministério do Trabalho. Diante desta política neoliberal, houve resistência da Rede Federal de Educação, que vivenciava o processo de "cefetização".

A aprovação da LDB também será abordada neste artigo, pois a lei não tratou com o rigor necessário o ensino profissional de nível médio, ofertado principalmente nas Escolas Técnicas Federais, Escolas Agrícolas Federais e em alguns poucos sistemas estaduais. Como explica Moura (2007), a lei favoreceu principalmente a iniciativa privada, que pôde atuar livremente na educação em todos os níveis.

Por fim, será abordada a implantação do novo ensino médio nas instituições federais de educação, que tiveram prazo de quatro anos para se adequarem ao plano de implantação, pela Portaria MEC nํ. 646 de 14 de maio de 1997, que regulamentou os artigos 39 a 42 da LDB e o Decreto ํo 2.208/97.

Entre outros assuntos, esse documento determinou que 0 ingresso dos estudantes, no ano de 1998, deveria ocorrer seguindo o novo formato, isso é, o ensino profissional deveria ocorrer de forma concomitante ao ensino médio ou por meio de cursos pós-médio. Além disso, a oferta do ensino médio regular não deveria ser superior a $50 \%$ das vagas das instituições.

A proibição do ensino integrado, que é definido por Ramos (2008), como a possibilidade ao acesso à cultura, a ciência e ao trabalho, por meio da educação básica e profissional, foi uma decisão controversa. Para analisar as políticas educacionais implementadas, nesse período, é importante refletir sobre as "questões de fundo", que estão relacionadas ao modo como essas escolhas foram feitas e aos caminhos tomados para sua implantação.

Essa pesquisa utiliza a pesquisa bibliográfica, além da análise de leis e documentos oficiais relacionados à educação profissional brasileira.

\section{A CONSTITUIÇÃO DE 1988 E A EDUCAÇÃO PROFISSIONAL}

Com o objetivo de conhecer as políticas públicas que iriam nortear a educação profissional no final do século XX, buscou-se analisar a Constituição de 1988, a fim de verificar se a esfera política de tal documento foi determinante nos desfechos que essa modalidade de ensino seguiu.

Segundo Caires e Oliveira (2016), a educação profissional não é tratada de maneira específica na legislação brasileira, mas há pontos que tratam sobre a 
obrigatoriedade de uma educação voltada para o trabalho. Esse é o caso do artigo 205 da Constituição, que obriga o estado a fornecer preparo para o exercício da plena cidadania dos indivíduos, assim como a sua qualificação para o trabalho. O inciso IV do artigo 214 da Constituição de 1988 expõe a necessidade da elaboração de um Plano Nacional de Educação, em consonância com ações federais em diversas esferas do poder público, levando em consideração a formação para o trabalho (BRASIL, 1988).

O inciso XXXII do artigo $7^{\circ}$ busca a superação da dualidade estrutural da sociedade brasileira, proibindo a distinção entre trabalho manual, técnico e intelectual. A educação brasileira é historicamente marcada por diferenciar o ensino voltado para as classes mais favorecidas economicamente, priorizando o pensar para os mais abastados e o para os menos favorecidos, reservando o fazer prático, com apelo de acolhimento social.

Assim, a Constituição de 1988 propõe quase que um desafio na busca por desenvolver uma educação que atenda à necessidade do século $\mathrm{XXI}$, com um projeto educacional para a formação humana e para o trabalho, mesmo sem marcar pontos, que tratassem especificamente sobre a educação profissional.

A educação se transformou em um campo de muita disputa na construção da Constituição de 1988. O campo progressista conseguiu algumas conquistas esperançosas nesse momento, mas que, na maioria das vezes, não se consolidaram em vitórias nos anos seguintes. A luta por formas de ensino mais igualitárias, na perspectiva da superação da divisão social do trabalho, dividiu espaços com políticas neoliberais. Como argumentado por Moura (2007), a principal polêmica na educação continuou sendo o conflito dos que defendem a educação pública, laica, gratuita e de qualidade para todos contra os defensores da submissão dos direitos sociais, sob a alegação da necessidade de diminuir gastos.

\section{PRIMEIRA METADE DA DÉCADA DE 1990}

Nos primeiros anos da década de 1990, o Brasil começava a sua redemocratização. Após 21 anos de ditadura militar, o clima era de esperança e as discussões sobre o rumo que o país tomaria eram constantes. Com a Constituição promulgada, começavam as iniciativas para a construção da nova identidade da educação brasileira:

O balanço no campo educativo da década de 1990 indica que pelo fato de haver forte mobilização política, sindical, dos intelectuais, dos artistas e dos movimentos sociais engajados na luta democrática, mantinha-se a esperança de que a conclusão da transição para a democracia, e com sentido progressista, poderia ocorrer, com as eleições de 1989. (FRIGOTTO, 2006, p. 42).

Após a promulgação da Constituição de 1988, iniciou-se o debate sobre a Lei de Diretrizes e Bases da Educação Nacional 9394/1996 que, conforme Caires e 
Oliveira (2016), contemplou um capítulo sobre a formação técnica profissional, criando um conselho nacional no artigo 59, responsável pela formulação e coordenação de políticas públicas ligadas ao ensino técnico. O artigo 61 da LDB tratou do financiamento dessa modalidade de educação, com recursos provenientes da União, dos estados, dos municípios, além da contribuição de empresas, convênios e doações.

O ensino de nível médio sempre foi conflituoso e com o crescimento do neoliberalismo no meio econômico brasileiro, a educação também sofreu com a interferência internacional em suas políticas públicas. Em 1989, foi publicado um Relatório do Banco Mundial sobre o Ensino de 2 Grau no Brasil. O relatório apresentou determinações para o governo brasileiro a respeito desse nível de ensino (CAIRES; OLIVEIRA, 2016).

Este relatório detalhou a descrição do sistema escolar nacional, e como relata Garcia e Lima Filho (2004), acusou as razões que determinam, segundo o Banco, a ineficiência e ineficácia da escola pública brasileira. O relatório insiste no "fracasso" das políticas para o Ensino Médio e impõe um conjunto de políticas educacionais dirigidas, como condição para concessão de empréstimos, especialmente para a descentralização da gestão educacional e a introdução de testes padronizados para a avaliação de rendimento escolar dos alunos.

Para esse organismo internacional, o gasto com os alunos das Escolas Técnicas Federais era muito elevado, se comparados aos das escolas estaduais e municipais, então, propôs três ações direcionadas às escolas técnicas, segundo Garcia e Lima Filho (2004):

- Introduzir o pagamento de anuidades, utilizando o sistema de crédito educativo e/ou a cobrança de taxas, conforme as possibilidades financeiras dos alunos;

- Atrair mais alunos carentes para essas escolas;

- Expandir o número de matrículas, mais rapidamente do que construir novas escolas, visando a redução do custo por aluno.

Esse relatório tinha como intenção a privatização das Escolas Técnicas Federais e Centros Federais de Educação Tecnológica:

Notadamente, as sugestões do Banco Mundial para as Escolas Técnicas Federais estavam embasadas em fundamentos econômicos de viés neoliberal, traduzidos na valorização das privatizações e no desestímulo a ampliação das escolas públicas, sobretudo, as ligadas à formação tecnológica (CAIRES; OLIVEIRA, 2016, p. 99).

Nessa conjuntura, inicia-se, na década de 1990, a redemocratização estabelecida pelas eleições diretas ocorridas em 1989 que elegeu Fernando Collor de Mello, que, segundo Caires e Oliveira (2016), foi a primeira grande reação contra a nova Constituição, pois as principais ações do presidente eleito foram reduzir os direitos sociais, ecológicos, de gênero e as demarcações de terras indígenas e quilombolas, temas garantidos na Constituição de 1988. 
Com o novo presidente, vieram inúmeras medidas que favoreceram o mercado financeiro, como o confisco das poupanças que se aliava ao discurso sobre a necessidade de levar o país para a modernidade. Na prática, o governo buscava atender aos organismos internacionais abrindo o mercado e restringindo direitos sociais.

A educação passou a ter um papel central nos interesses empresariais e governamentais recebendo uma maciça intervenção estrangeira. Caires e Oliveira (2016) listam essas instituições: Fundos das Nações Unidas pela Infância (UNICEF), o Fundo Monetário Internacional (FMI), a Comissão Econômica para a América Latina e o Caribe (CEPAL), além de entidades empresariais nacionais como o Instituto Euvaldo Lodi (IEL) e o Instituto Herbert Levy (IHL).

Em 1990, o Brasil participou da $1^{\text {a }}$ Conferência de Educação para todos, realizada na Tailândia, passando a adotar um discurso de que a Educação profissional necessitava preparar o trabalhador para várias habilidades e capacitá-lo para o mercado globalizado.

Com a flexibilização da produção, na perspectiva de Kuenzer e Grabowski (2016), o capital acabou se apropriando também da subjetividade do trabalhador, precisando assim de um sujeito mais adaptável às diversas funções, que não dominasse o processo completo, mas sim várias partes dele, se isentando do questionamento das suas condições de trabalho. Políticas públicas que promovessem o ensino integrado foram sendo rejeitadas, contrariando a tendência da Constituição de 1988 e das primeiras discussões sobre a LDB 9.394/1996.

A educação técnica durante a década de 1990 manteve a tendência de servir aos interesses do mercado financeiro, pois como relatam Araujo e Frigotto (2005), o currículo sendo um campo ideológico, priorizava uma visão de mundo vinculado aos interesses das classes dominantes, enquanto as subalternas se sentem incapazes de mudar a própria realidade.

As ações sugeridas pelo Banco Mundial não foram acatadas para a Rede Federal de Escolas Técnicas, durante o governo Collor, o que não significou que as políticas públicas para a educação profissional não permaneceram submetidas aos ideais neoliberais. Para promover a gestão da educação profissional, como explica Caires e Oliveira (2016), foi criada pelo MEC (Ministério da Educação e Cultura), a Secretaria Nacional de Educação Tecnológica (SENETE), que passou a ser responsável pelas ações de desenvolvimento, promoção e coordenação da formação tecnológica.

Caberia a esta secretaria "subsidiar as instituições de Educação Tecnológica na implementação de ações concretas, levando em consideração a evolução científica e tecnológica, com reflexos no mundo do trabalho, dentro da visão atual e prospectiva da realidade" (BRASIL, 1992a, apud GARCIA; LIMA FILHO, 2004).

Conforme a concepção do governo Collor, a Educação Tecnológica guardava o compromisso prioritário com o futuro, no qual o conhecimento vinha se transformando no principal recurso gerador de riquezas, seu verdadeiro capital, exigindo uma renovação da escola, para que assumisse o papel de transformadora da realidade econômica e social do país (BRASIL, 1991, p. 57). Esse conceito estava afinado com a lógica do capital: 
Neste conceito de educação tecnológica formulado pela SENETE, ressurge, então, a velha retórica da educação redentora dos males sociais. A retórica do valor econômico da educação é acompanhada, agora em sua roupagem neoliberal, dos paradigmas da competitividade e da modernização o que, no campo das políticas educacionais, passou a orientar a aproximação das instituições do ensino técnico ao mundo empresarial, sobretudo, pela recomendação de que tais instituições deveriam adotar o modelo de gestão da iniciativa privada, dotado de flexibilidade e operacionalidade no âmbito da lógica mercantil (GARCIA; LIMA FILHO, 2004, p. 17).

Inicialmente, como relata Kuenzer (2007), a SENETE propôs um sistema paralelo ao sistema educacional chamado Sistema de Educação Tecnológica, que abrangia as instituições de ensino mantidas pelo setor público federal, estadual e municipal e por instituições particulares, incluindo o SENAC (Serviço Nacional de Aprendizagem Comercial) e o SENAI (Serviço Nacional de Aprendizagem Industrial), dando a essa educação a tarefa messiânica de salvamento do país.

Em paralelo, ocorria também o movimento de transformação das Escolas Técnicas Federais em CEFETs, processo conhecido como "cefetização". As instituições buscavam seguir o exemplo das experiências iniciais das Escolas Técnicas Federais do Paraná, Minas Gerais e Rio de Janeiro, que foram transformadas, por meio da Lei $n^{\circ} 6.545$, de 30 de junho de 1978, em Centros Federais de Educação Tecnológica, mais conhecidos como CEFETs.

Durante este período, houve uma ampliação da autonomia administrativa e pedagógica dos CEFETs, reforçaram a sua excelência como centros de educação técnica e tecnológica. Com um discurso de valorização da produção científica e tecnológica como veículo da modernização do país, várias Escolas Técnicas Federais passaram a reivindicar sua transformação em Centros Federais de Educação Tecnológica (GARCIA e LIMA FILHO, 2004):

[...] apresentada em 1991 pela Secretaria Nacional de Educação Tecnológica do Ministério da Educação, com participação da Secretaria de Ciência e Tecnologia da Presidência da República: a constituição do Sistema Nacional de Educação Tecnológica, um sistema de ensino paralelo ao sistema nacional e regular de educação, com gestão e objetivos específicos, cuja espinha dorsal seria formada pela rede de Centros Federais de Educação Tecnológica e que deveria "articular as várias iniciativas de educação profissional, definir políticas e normas e delimitar as diversas áreas de atuação dos diferentes órgãos de modalidades [...]" , (GARCIA; LIMA FILHO, 2004, p. 18).

O modelo institucional dos CEFETs foi considerado, no discurso governamental, o mais adequado aos novos requerimentos quanto à formação, em nível técnico e tecnológico, de profissionais flexíveis e dotados de capacidade de adaptação e iniciativa diante dos desafios da globalização e das transformações do mundo do trabalho (GARCIA; LIMA FILHO, 2004). 
No campo político, não levou muito tempo para o presidente Collor mostrar falta de habilidade na implantação do ideário neoliberal e, em setembro de 1992, sofreu um processo de impeachment, sendo substituído pelo seu vice, Itamar Franco.

O presidente Itamar Franco reorganizou os ministérios e a SENETE foi transformada em SEMTEC (Secretaria de Educação Média e Tecnológica). Essa nova secretaria, representava um novo horizonte nas políticas públicas para a educação profissional, porém a nova secretaria não conseguiu fazer avanços na superação do aspecto dual entre ensino técnico e o científico (CAIRES; OLIVEIRA, 2016).

$\mathrm{Na}$ década de 1990, a organização do trabalho sofreu uma importante mudança, a flexibilização da produção influenciou a educação, que passou a trazer no seu discurso, questões como o livre mercado, competitividade, automação, empregabilidade. Essa foi a lógica tanto do governo Itamar Franco, quanto a do seu sucessor, Fernando Henrique Cardoso, eleito em 1994 (CAIRES; OLIVEIRA, 2016).

Em agosto de 1995, a SEMTEC, tomando por base o Planejamento PolíticoEstratégico 1988/1995, anunciou seu posicionamento em relação às políticas voltadas para as escolas técnicas da Rede Federal. Acácia Kuenzer (2007) expõe quais eram os principais pontos que seriam abordados:

- Estrutura do ensino médio (reforma curricular);

- A expansão do atendimento;

- A consolidação e descentralização da rede de Escolas Técnicas e CEFETs;

- A avaliação;

- O ensino a distância.

A estratégia de gestão da Rede Federal de Educação Tecnológica era a de separar o ponto de vista conceitual do operacional, ou seja, a parte profissional da parte acadêmica (KUENZER, 2007).

Foi uma época marcada por grandes conflitos no que se refere à educação profissional, pois havia, de um lado, educadores e estudiosos da área que defendiam uma educação pública, gratuita, laica e de qualidade para todos, independentemente da origem socioeconômica, étnica e racial. Por outro lado, havia o Governo Federal que tentava implementar uma formação fragmentada e flexível, sem compromisso com a formação integral dos trabalhadores.

\section{A SEGUNDA METADE DA DÉCADA DE 1990}

Ignorando a discussão de especialistas do campo da educação profissional, o Governo Federal apresentou o Projeto de Lei no 1.603/1996, que atendia às orientações do Banco Interamericano de Desenvolvimento (esse organismo não financiava projetos sem impor suas condições), que determinava uma nova organização para a Rede Federal de Educação, que atendia às demandas neoliberais.

Partia-se de um raciocínio de que ensino superior não era para todos, mas sim para dirigentes e técnicos de alto nível. Estudantes bem preparados nos $1^{\circ}$ e $2^{\circ}$ graus, rigorosamente selecionados como forma de prêmio. Os demais deveriam ser preparados para carreiras meramente operacionais. Esse projeto propunha uma série de medidas nesse sentido. Obviamente enfrentou grande resistência entre os pensadores da educação. (KUENZER, 2007). 
Depois de oito anos de discussão, a nova LDB 9.394/96, apresentou as novas regras para o ensino técnico, no qual praticamente excluía o $2^{\underline{a}}$ grau profissionalizante no país, exceto nas Escolas Técnicas Federais, Escolas Agrícolas Federais e em alguns poucos sistemas estaduais. De acordo com os artigos do capítulo 3 da LDB 9.394/96, a educação profissional estava assim configurada:

Art.39 - A educação profissional, integrada às diferentes formas de educação, ao trabalho, à ciência e à tecnologia, conduz ao permanente desenvolvimento de aptidões para a vida produtiva.

Parágrafo único. O aluno matriculado ou egresso do Ensino Fundamental, Médio e Superior, bem como o trabalhador em geral, jovem ou adulto, contará com a possibilidade de acesso à educação profissional.

Art. 40 - A educação profissional será desenvolvida em articulação com o ensino regular ou por diferentes estratégias de educação continuada, em instituições especializadas ou no ambiente de trabalho.

Art. 41 - O conhecimento adquirido na educação profissional, inclusive no trabalho, poderá ser objeto de avaliação, reconhecimento e certificação para prosseguimento ou conclusão de estudos.

Parágrafo único. Os diplomados de cursos de educação profissional de nível médio, quando registrados, terão validade nacional.

Art. 42 - As escolas técnicas e profissionais, além dos seus cursos regulares, oferecerão cursos especiais, abertos à comunidade, condicionada a matrícula à capacidade de aproveitamento e não necessariamente ao nível de escolaridade (BRASIL, MEC, 1996a).

Moura (2007), ao se referir a Constituição de 1988 e à LDB/1996, afirma que a educação de nível médio praticamente separava a educação acadêmica, da educação técnico-profissionalizante, sendo esta modular e de curta duração, prevalecendo a lógica de mercado, favorecendo a iniciativa privada, que pôde atuar livremente na educação em todos os níveis.

Os estudantes ficaram com duas opções de se profissionalizarem no Ensino Médio. A primeira, após o Ensino Médio, cursando a Educação Profissional na modalidade pós-médio (subsequente) e a segunda se matriculando concomitantemente, a partir do segundo ano do Ensino Médio. Esta última opção obrigava o estudante a frequentar duas escolas: a de Ensino Médio e a de Educação Profissional, já que as escolas que ministravam o Ensino Médio não poderiam oferecer a Educação Profissional. (NEY, 2006).

A educação brasileira, na LDB 9.394/96, ficou estruturada em dois níveis: a educação básica e a educação superior. A educação profissional não está incluída em nenhum dos dois, consolidando uma dualidade bastante explícita, já que o ensino profissionalizante não faz parte da estrutura da educação regular brasileira, pois passou a ser considerada como algo em paralelo ou como um apêndice, sendo assim tratada como modalidade, o que efetivamente não é correto. (MOURA, 2007).

Como já era de se esperar essa medida sofreu uma forte resistência. Forças políticas das mais diversas correntes dentro do Congresso Nacional, a comunidade 
acadêmica, principalmente dos grupos de investigação do campo da educação e trabalho, as ETFs (Escolas Técnicas Federais), os CEFETs e entidades sindicais, se uniram em oposição a essa política educacional. (MOURA, 2007).

Para financiar a reforma da educação profissional, o governo federal negociou um novo empréstimo, junto ao BID (Banco Interamericano de Desenvolvimento), como parte do projeto de privatização do Estado Brasileiro, em atendimento à política neoliberal. Esse financiamento foi materializado por meio do Programa de Expansão da Educação Profissional (PROEP) criado no ano de 1997.

O PROEP foi uma parceria entre o MEC, Ministério do Trabalho e o BID, coordenado pela SEMTEC, que contava com o aporte de 500 milhões de dólares para a implementação ou adequação de Centros de Educação Profissional, atraindo instituições privadas de todos os aspectos.

A função da PROEP era reestruturar a Rede em suas ofertas educacionais, buscando intensificar a relação empresarial com as escolas, com interesse para 0 autofinanciamento, diminuindo a responsabilidade do estado. Assim os recursos públicos para manutenção foram diminuídos. As grandes empresas passaram a financiar alguns cursos e a direcioná-los para seus interesses. Neste modelo, a educação politécnica ${ }^{1}$ foi posta de lado:

[...] a fragilidade da relação entre o Ensino Médio e a Educação Profissional e a não preocupação com uma sólida formação politécnica evidenciam a aproximação com as propostas neoliberais, priorizadas no mundo globalizado e flexível, que tem demandado, na atualidade, uma capacitação voltada para a formação de trabalhadores adaptáveis à transitoriedade e à competitividade dos mercados capitalistas (CAIRES; OLIVEIRA, 2016, p. 109).

A Secretaria de Formação e Desenvolvimento Profissional (SEFOR), vinculado ao Ministério do Trabalho, financiada pelo Fundo de Amparo ao Trabalhador (FAT), criou o Plano Nacional de Qualificação do Trabalhador (PLANFOR) pela Resolução no 126, de 23 de outubro de 1996. Esse programa tinha como objetivo garantir a qualificação e a requalificação profissional para trabalhadores ativos (CAIRES; OLIVEIRA, 2016).

A LDB 9.394/96, não impedia a integração entre o Ensino Médio e a Educação Profissional de nível Técnico, então para selar definitivamente o direcionamento desse tipo de educação, o Conselho Nacional de Educação regulamentou por meio do Decreto n․ 2.208/1997, a obrigatoriedade de desintegração do ensino regular e o profissional.

As instituições federais de Educação Tecnológica tiveram um prazo de quatro anos para a implementação do novo ensino médio, por meio do plano de implantação exigido pela Portaria no. 646 de 14 de maio de 1997. Entre outros assuntos, esse

1 Educação Politécnica representa o domínio da técnica a nível intelectual e a possibilidade de um trabalho flexível com a recomposição das tarefas a nível criativo. (MACHADO, 1992). 
documento determinou que o ingresso dos alunos no ano de 1998, deveria ocorrer seguindo as novas regras, isso é, de forma concomitante ou subsequente e que a ofertas de vagas no ensino médio regular não poderiam ser superior a $50 \%$ das vagas da instituição.

Essa situação criou desânimo nas instituições e o número de matrícula na educação profissional caiu consideravelmente. Essa reforma foi amplamente criticada pelos estudiosos brasileiros, especialmente da linha educação e trabalho, e pela comunidade cefetiana (CAIRES; OLIVEIRA, 2016).

O artigo $3^{\circ}$ da Lei nํ 8.948/94, que trata da transformação das Escolas técnicas Federais em Centros Federais de Educação, passou a vigorar acrescido do seguinte parágrafo:

$5^{0}$ - A expansão da oferta de educação profissional, mediante a criação de novas unidades de ensino por parte da União, somente poderá ocorrer em parceria com estados, municípios, Distrito Federal, setor produtivo ou organizações não-governamentais, que serão responsáveis pela manutenção e gestão dos novos estabelecimentos de ensino [...]. (BRASIL, 1994).

Quase ao final das discussões sobre a LDB 9394/96, surgiu o PL. 1.603/96, um projeto de lei elaborado pelo MEC sob a liderança do ministro Paulo Renato de Souza, que propunha a reforma da educação profissional, principalmente, para a Rede Federal, causando um desgaste nos debates sobre o tema, assim o texto final da LDB foi aprovado, deixando o capítulo sobre educação profissional bastante vago.

A Lei de Diretrizes e Bases para Educação, segundo Moura (2007), permitiu todas as possibilidades em relação à modalidade, a de articulação entre o ensino médio e a educação profissional, mas também a completa desarticulação entre eles. Essa redação apaziguou os ânimos do governo federal e dos grupos que resistiam à obrigação da separação entre ensino médio e a educação profissional.

Essa atitude não foi inocente nem desinteressada, pelo contrário, o objetivo era recuperar forças para consolidar a separação entre o ensino médio e a educação profissional o que ocorreu por meio do PL n- 1.603/96 de iniciativa do governo Fernando Henrique Cardoso.

O Ministério acabou transformando o PL no Decreto no 2.208/97. Esse Decreto veio trazer materialidade ao $P L n^{0} 1.603 / 96$ que teve dificuldade no processo de tramitação. O Decreto, portanto, concretizou a reforma da Educação Profissional que o texto da Lei de Diretrizes e Bases da Educação não havia realizado (GARCIA, 2009).

Fortalecendo ainda mais a lógica neoliberal, foi instituído o Decreto n.․ 2.208/97 promovendo os três níveis para a Educação Profissional e Tecnológica: básico, técnico, e tecnológico, sendo o último ofertado em nível superior, com carga horária significativamente menor do que as demais carreiras da educação superior (MOURA, 2007). 
Essa combinação de fatores, junto com a supervalorização social do diploma de nível superior, fez crescer sem precedentes o número de cursos superiores de tecnologia nas instituições privadas, porém sem controles eficientes sobre sua qualidade (MOURA, 2007).

Moura (2007) esclarece que não se deveriam permitir cursos superiores de tecnologia oferecidos em larga escala por instituições particulares, junto com as proporcionadas pelos CEFETs, que foram concebidos apenas para atender à lógica do mercado.

As políticas educacionais para a EPT na década de 1990 foram marcadas por muita disputa, na qual a vertente neoliberal conseguiu mais avanços, trazendo muitos prejuízos para a educação na perspectiva unilateral.

\section{CONSIDERAÇÕES FINAIS}

Desde as discussões sobre a constituição de 1988, a educação é alvo de disputas, entre grupos que desejam a elitização e grupos que lutam pela sua democratização, sendo que o ensino médio se mantém no centro desse impasse.

O ensino integrado mesmo apresentando uma forma mais justa e igualitária de educação, causa desinteresse nos grupos políticos, que representam o poder econômico educacional.

Os anos de debate sobre a LDB 9394/96 não foram suficientes para a construção de uma política pública consistente, no que se refere ao ensino profissional. O Projeto de Lei $\mathrm{n}^{0}$ 1.603/96, que previa a desintegração e consequentemente a segregação dos estudantes, foi exaustivamente combatida e resultou em uma LDB esvaziada nas questões da educação para o trabalho técnico. Para enfim, o Decreto n 2.208/97 acaba materializando o mal-intencionado projeto de lei.

As determinações do Decreto n. 0 2.208/97 acarretaram na queda da qualidade do ensino em decorrência da extinção da integração entre educação geral e educação profissional, reforçando a lógica dualista existente no país.

O ensino médio integrado sofreu duros golpes no decorrer da década de 1990. A desigualdade aumentou entre os que são formados para o trabalho manual e os que são direcionados ao trabalho intelectual.

Por outro lado, a organização da luta por uma educação profissional, que emancipe o trabalhador começou a se fortalecer. Esse esforço acabou resultando na criação da Rede de Institutos Federais de Ciência e Educação, pela Lei no 11.892/2008, que tem como objetivo, ofertar uma educação integrada. 


\section{REFERÊNCIAS}

BRASIL. Constituição da República Federativa do Brasil: promulgada em 5 de outubro de 1988. 25. ed. atual e ampla. São Paulo: Saraiva, 2000.

BRASIL. Decreto no 2.208, de 17 de abril de 1997. Regulamenta o §2ㅇdo art. 36 e os artigos 39 a 42 da Lei n. 9.394, de 20 de dezembro de 1996, que estabelece as Diretrizes e Bases da Educação Nacional. Diário Oficial da União, Brasília, p. 7.760/1, 18 abr. 1997.

BRASIL. Lei o 8.948, de 8 de dezembro de 1994. Diário Oficial da União. Dez. 1994. Brasília. Disponível em: http://www.planalto.gov.br/ccivil 03/leis/L8948.htm. Acesso em: 16 de julho de 2020.

BRASIL. Lei no 9.394, de 20 de dezembro de 1996. Diário Oficial da União, 23 dezembro. 1996a. Brasília. Disponível em: http://www.planalto.gov.br/ccivil 03/leis//93994.htm. Acesso em: 16 de julho de 2020. BRASIL. MEC/ SENETE. O Sistema Nacional de Educação Tecnológica. Brasília, 1991. Disponível em: http://portal.mec.gov.br/setec/arquivos/pdf/p publicas.pdf. Acesso em: 17 de julho de 2020.

BRASIL. Projeto de Lei no 1603, de 4 de março de 1996. Dispõe sobre a Rede Federal de Educação Profissional e das Outras Providências.

BRASIL. Portaria Ministerial no 646, de 14 de maio de 1997. Regulamenta a implantação do disposto nos artigos 39 a 42 da Lei Federal no 9.394/96 e no Decreto Federal no 2.208/97 e dá outras providências (trata da rede federal de educação tecnológica). Disponível em http://portal.mec.gov.br/setec/arquivos/pdf/PMEC646_97.pdf: Acesso em: 17 de julho de 2020.

CAIRES, Vanessa Guerra; OLIVEIRA, Maria Auxiliadora Monteiro Oliveira Educação Profissional Brasileira: da Colônia ao PNE 2014-2024.Petrópolis/RJ: Editora Vozes, 2016.

CIAVATTA, Maria. A Formação Integrada: A Escola e o Trabalho como Lugares de Memória e de Identidade. Trabalho Necessário, v.3, n.3, p.1-20, 2005.

CIAVATTA, Maria. Mediações Históricas de Trabalho e Educação: Gênese e Disputas na Formação dos Trabalhadores (Rio de Janeiro, 1930-60). Rio de Janeiro: Lamparina, 2009.

FRIGOTTO, Gaudêncio. Anos 1980 e 1990: A Relação entre o Estrutural e o Conjuntural e as Políticas de Educação Tecnológica e Profissional. In: FRIGOTTO, Gaudêncio; CIAVATTA, Maria. A Formação do Cidadão Produtivo: A Cultura de Mercado no Ensino Médio Técnico. Brasília, p. 25 - 54, 2006.

GARCIA, Nilson Marcos Dias; LIMA FILHO, Domingos Leite. Politecnia ou Educação Tecnológica: Desafios ao Ensino Médio e à Educação Profissional. In: Anais da 27ª reunião anual da ANPEd. ANPEd: Caxambu, 2004.p. 1-34, 2004.

GARCIA, Sandra Regina de Oliveira. A educação Profissional Integrada ao Ensino Médio no Paraná: Avanços e Desafios. Curitiba, 2009, 147 f. Tese (Doutorado em 18 
Educação). Universidade Federal do Paraná, Setor de Educação, Programa de PósGraduação em Educação, UFPR, 2009.

GRABOWSKI, Gabriel; KUENZER, Acácia Zeneida. A produção do Conhecimento no Campo da Educação Profissional no Regime de Acumulação Flexível. Holos, v. 6, p. 22-32, 2016.

KUENZER, Acácia. Ensino Médio e Profissional: As Políticas do Estado Neoliberal. 4 ed. São Paulo: Cortez, 2007.

MACHADO, Lucília Regina de Souza. Mudanças Tecnológicas e a Educação da Classe Trabalhadora. In: CBE - Conferência Brasileira de Educação. Trabalho e Educação. Campinas: Papirus, 1992.

MOURA, Dante Henrique. Educação Básica e Educação Profissional e Tecnológica: Dualidade Histórica e Perspectiva de Integração. Holos, Natal, v.2, p.1-27, 2007.

MOURA, Dante Henrique. Ensino Médio Integrado: Subsunção aos Interesses do Capital ou Travessia para a Formação Humana Integral? Educação Pesquisa, v. 39, n. 3, p. 705-720, 2013.

NEY, Antonio Fernando Vieira. A Reforma do Ensino Médio Técnico: Concepções, Políticas e Legislação. In: FRIGOTTO, Gaudêncio; CIAVATTA, Maria. A Formação do Cidadão Produtivo: A Cultura de Mercado no Ensino Médio Técnico. Brasília, 2006, p. 259-282, .

RAMOS. Marise Nogueira. Concepção do Ensino Médio Integrado. In: Seminário sobre Ensino Médio, 2008. Secretaria de Educação do Pará. 08-09 maio 2008.

RAMOS. Marise Nogueira. História e Política da Educação Profissional. Coleção Formação Pedagógica. Volume 5. IFPR-EAD. Curitiba, 2014.

OLIVEIRA, Francisco de. A Nova Hegemonia da Burguesia no Brasil dos Anos 1990 e os Desafios de uma Alternativa Democrática. In: FRIGOTTO, Gaudêncio; CIAVATTA, Maria. Teoria e Educação no Labirinto do Capital. São Paulo. Expressão Popular, p. 87-127, 2016. 